\title{
Spatio-temporal travel characteristics of the elderly in an ageing society
}

(submitted to Travel Behaviour and Society for publication consideration)

\begin{abstract}
Hong Kong's population is ageing at an unprecedented and considerable rate, predominantly due to sustained low fertility and mortality rates. In 2013, the proportion of people aged 60 years or above was the second highest in Asia, exceeded only by that in Japan. Given that Hong Kong is a high-density, transit-oriented city, the predicted rapid growth of its elderly population is expected to significantly affect the existing public transport systems. To provide suitable policy recommendations that cater to the travel needs of an ageing society, we must investigate and understand the travel behavior and preferences of Hong Kong's elderly citizens. In this study, we extracted the household interview survey data from the 2011 Travel Characteristics Survey to identify the travel patterns of the elderly and compare them with other age cohorts and among subgroups of the elderly population. We visualize and uncover the spatio-temporal travel characteristics of the elderly, and offer policy insights that promote age-friendly public transport systems. We believe that the findings and discussions herein will prove useful in future studies aiming to establish effective and appropriate public transport policy measures to improve elderly mobility.
\end{abstract}

Keywords: Spatio-temporal travel characteristics; Elderly; Ageing society; Household interview survey; Public transport policy measures; High-density and transit-oriented cities

\section{Introduction}

Population ageing has become a notable and common demographic phenomenon in most countries. The proportion of the population aged 60 years or over is growing substantially, with the number of elderly in the world projected to grow by $56 \%$, from 0.9 billion to 1.4 billion, between 2015 and 2030. Research has also shown that there will be 2.0 billion elderly adults by 2050, constituting an even larger share of society, with about $80 \%$ of them living in developing countries (United Nations, 2015). Obviously, this anticipated rapid growth in the elderly population poses a great challenge for transport operators and urban planners tasked with offering travel options that consider the unique and complex travel patterns of the elderly (Alsnih and Hensher, 2003; Hess, 2009). Thus, it is generally believed that ageing's effect on transport systems should receive more attention, compared with the other challenges that ageing poses for the economy and for health care and retirement systems (Buehler and Nobis, 2010).

\subsection{Ageing population in Hong Kong}

Predominantly due to sustained low fertility and mortality rates, the population in Hong Kong is ageing at an unprecedented and considerable rate. In 2015, the percentage of elderly people aged 60 or above in Hong Kong was $21.7 \%$, the second highest in Asia and exceeded only by Japan, which topped the global list (United Nation, 2015). According to population projection data for 2012-2041, the proportion of people aged 60 or above is expected to reach 36.3\% in 2041 (Census and Statistics Department, 2012). Indeed, Hong Kong's ageing population has already created numerous social and economic challenges, such 
as health care, the old age allowance, and senior residence provisions (Financial Services and the Treasury Bureau, 2013). Unfortunately, the effects of ageing populations on transport systems have been largely ignored by government officials and policy makers, such that the existing transport system is inadequate to support the striking increase in the elderly population in the near future. There is no doubt that improvements in elderly mobility facilitate the promotion of overall societal development, especially in the transport sector (Olawole and Aloba, 2014). Therefore, such improvements should be a top priority for transport policy makers. The vision of "Transport for All," which initiates the development of a transport system accessible to all people to improve mobility, has been emphasized in Hong Kong's transport policies. Particular attention has been paid to the needs of the disabled, but few policies have targeted the needs of senior citizens. Although the transport needs of elderly and disabled people are vastly different, the current transport policy measures for the former are essentially identical to those developed to meet the needs of the latter, which may not be sufficient to guarantee the former's mobility.

To provide suitable policy recommendations that consider the considerable growth in ageing populations in Hong Kong, a prerequisite is to investigate and understand the travel behavior of elderly citizens. Hence, it is of paramount importance to conduct a comprehensive study on their daily travel patterns and spatio-temporal travel characteristics. In an effort to understand and improve elderly mobility, numerous studies have focused on the travel patterns of the elderly in Western countries, particularly the United States and Europe (Hildebrand, 2003; Buehler and Nobis, 2010; Currie and Delbosc, 2010; Ipingbemi, 2010; King and Scott-Parker, 2016; Rahman et al., 2016; van den Berg et al., 2016). In most of the countries concerned, driving is the primary means of transport, and only a small proportion of elderly people use public transport services. For example, the transit share in the United States is only $1.9 \%$ (Department of Transportation, 2011). Likewise, in most European countries, such as the United Kingdom, Germany, and Denmark, the transit shares are less than 20\% (European Environment Agency, 2009). In contrast, Hong Kong is a unique city, where nearly $90 \%$ of the population uses public transport and only a few of them use private vehicles. Therefore, the public transport policy measures suggested in the literature are not appropriate in the Hong Kong context.

\subsection{Travel characteristics of the elderly}

To improve the mobility of the elderly, numerous studies with varying degrees of depth and sophistication have focused on their travel patterns and behavior (Hildebrand, 2003; Buehler and Nobis, 2010; Currie and Delbosc, 2010; Ipingbemi, 2010; Rahman et al., 2016; van den Berg et al., 2016). Traditional travel demand modeling generally assumes travel activities to be age-related (Figueroa et al., 2014). As age increases, the willingness and ability to drive decrease, resulting in decreased travel activity, journey time, and distance. Johansson-Stenman (2002) found that travel distance reaches its peak at about the age of 50 . In addition, the observable trend becomes significant once retirement age is reached (Collia et al., 2003; Somenahalli and Shipton, 2013). Despite this, today's elderly individuals appear to be as mobile as their younger counterparts with respect to the number of trips. Interestingly, the elderly were more likely to have a driver's license, take more trips, and drive more than older adults a decade ago. The elderly were more mobile than ever before, and the trends toward increased trip rates and distances could be witnessed. In a recent study, van den Berg et al. (2011) revealed that there are no significant age effects on travel distance and time among young adults and the elderly in the Netherlands.

Cars (for drivers and passengers alike) are the most important travel mode for the elderly in Western countries. In Canada, car drivers and car passengers were the two dominant 
transport modes for the elderly, with public transport (train and bus) ranked the most unpopular mode (Newbold et al., 2005). Similarly, Rosenbloom (2004) reported that in the United States, older adults made most of their trips by car, with only around $6 \%$ walking and $2 \%$ using public transit. The situation is similar in Australia, with the shares of automobiles and public transport being 83\% and 7\%, respectively (Truong and Somenahalli, 2015). Numerous studies have revealed that the shares of cars and taxis are much higher than those of buses, coaches, and rail in European countries. For example, in the United Kingdom, older adults (70 and above) make about $50 \%$ of their trips by private car (includes driving and carsharing) and only $12 \%$ by bus (Department of Environment, Transport and Regions, 2000). In the Netherlands, nearly $50 \%$ of the elderly aged 65 or above make their trips by car, with less than $10 \%$ made by public transport (Tacken, 1998). It is worth noting that as compared to the United States, European countries have a larger proportion of old adults depending on public transport services. However, due to the increasing car-accessible rate of the elder generation, the segment of the transport service-dependent seniors will probably shrink (Haustein and Siren, 2015; Siren and Haustein, 2016). In contrast, in a few developing countries such as China, characterized by lower car and driving license ownership rates, the elderly travel mostly on foot (49\%), followed by public transport (43\%), bicycle (4\%), and car (less than 1\%) (Hu et al., 2013).

For most of the elderly, work is no longer part of their activities. Hence, the changes generated by retirement can affect their trip-making behavior (van den Berg et al., 2011; Siren and Haustein, 2016). Beyond staying at home, the activities of the elderly include visiting, shopping, and recreational activities. For example, Newbold et al. (2005) stated that traveling for goods and services ranked first among all outdoor activities for the elderly in Canada. However, travelling to religious places constituted the highest proportion of total trips generated by the elderly in Nigeria (Olawole and Aloba, 2014). In Asian countries such as China, the two major trip purposes for the elderly were shopping (21\%) and leisure $(11 \%)(\mathrm{Hu}$ et al., 2013). Understandably, the travel patterns of the elderly are substantially different in differing settings. Considerable research has been conducted on the travel patterns of the elderly, but most have been focused on countries where driving is the primary means of mobility, with a very low patronage of public transport. Excellent review of earlier work was published by Cui et al. (2016) on travel behaviour and mobility needs of older adults in an ageing and car-dependent society. To the best of our knowledge, there are limited local studies revealing the travel patterns of the elderly in Hong Kong-a high-density, transitoriented city.

\subsection{Objectives of this research}

To reveal the travel patterns and behavior of Hong Kong's elderly population, this study investigates their basic travel characteristics based on the 2011 household interview survey data from the Travel Characteristics Survey (TCS2011) (Transport Department, 2014). This work illustrates and uncovers the spatio-temporal characteristics of elderly travel. Then, based on the findings, suggestions are made regarding how to improve public transport services for the elderly. The results will serve as a valuable reference for the city government in establishing effective and appropriate public transport policies that enhance elderly mobility.

The contributions of this paper include the following: 1) uncovering the travel patterns and preferences of local citizens in different age cohorts and genders based on household interview survey data; 2) presenting the spatio-temporal travel characteristics of the elderly and comparing them with those of young adults; and 3) discussing policy insights to improve public transport services for the elderly. 
The remainder of the paper proceeds as follows. Section 2 introduces the household interview survey data adopted in this study. Sections 3 and 4 present the findings of travel patterns and a spatio-temporal travel analysis of young adults and the elderly. Section 5 discusses the policy insights, and Section 6 concludes the paper and suggests a few research directions for future studies.

\section{Household interview survey data}

Household interview surveys have been widely used to study the travel patterns and behavior of the elderly in previous studies (e.g., Collia et al., 2003; Choi et al., 2014; Figueroa et al., 2014). However, as mentioned, there is scant literature on the travel behavior of older populations in high-density, transit-oriented cities such as Hong Kong. The travel characteristics of the elderly can be determined by taking advantage of the TCS2011 data (Transport Department, 2014). The TCS2011 was a self-reported attitudinal survey conducted by the Transport Department of Hong Kong SAR Government between September 2011 and March 2012. The data were obtained from a random sample of 101,385 local respondents in 35,401 households, with approximately a $1.5 \%$ sampling rate (the total number of households and the population count were 2,363,300 and 6,881,900, respectively). Quality control measures were strictly applied in the fieldwork periods to ensure high-quality data.

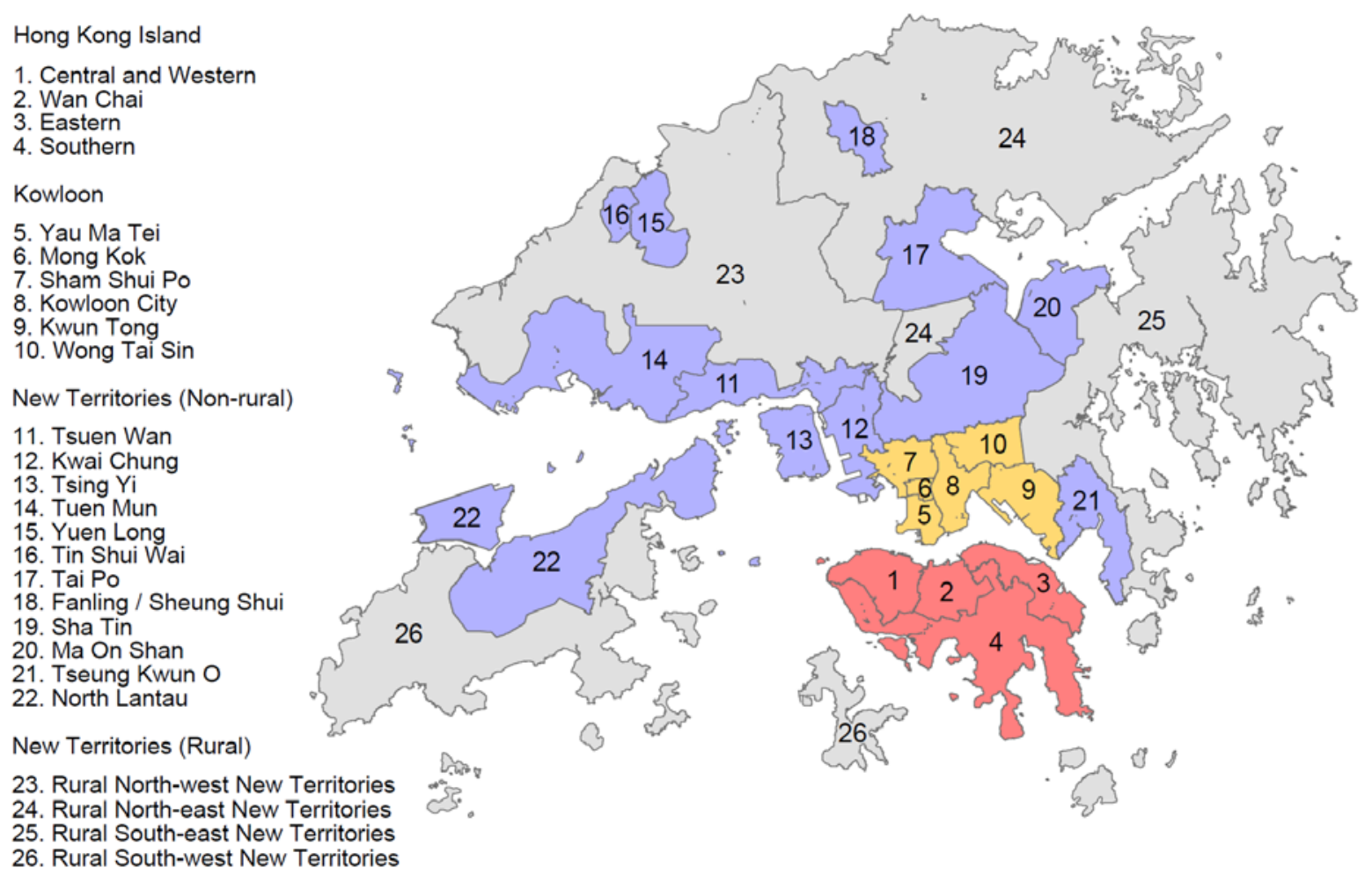

Fig. 1. Hong Kong territory's broad districts.

The household interview survey consists of three levels: 1) household data (including number of household members, housing type, private vehicle availability, etc.); 2) household members' personal particulars (including gender, age, occupation status, driver's license ownership etc.); and 3) a complete record of every trip involving mechanized transport (including departure and arrival time, origin and destination, transport mode used, trip purpose, interchange location, etc.) made within the past 24 hours (on a normal weekday, starting from $3 \mathrm{am}$ ) for every household member. Walking trips with the same start and end 
point that did not involve a mechanized transport mode were neglected. The collected survey data were processed and adjusted by the household expansion factor based on independent control data, such as population distribution in Hong Kong territory, to expand the householdrelated data (35,401 households) to be representative of the territory-wide total $(2,363,322$ households).

As Fig. 1 shows, Hong Kong territory was divided into 26 zones (broad districts) for transport planning and modeling analysis. Each zone had a certain degree of homogeneity in land use. Four zones were in Hong Kong Island (shown in red), six zones were in Kowloon (shown in yellow), twelve zones were in the New Territories non-rural area (shown in blue), and the remaining four zones were in the New Territories rural area (shown in grey). It is worth mentioning that the rural areas were much less populated than their urban counterparts.

\section{Trip patterns and behavior}

This section provides statistical analyses of the mechanized trip rate, journey time, mode choice, trip purpose, and daily profile of trip start time to compare the travel patterns of people in different age cohorts and genders.

\subsection{Trip rate: How many trips did the elderly travel by mechanized transport modes?}

To present the travel characteristics of the elderly and allow for comparisons with those of young adults, this study used the household interview survey data from Hong Kong respondents aged 18 or above. Data on children and teenagers were ignored because their travel patterns were considerably different, which could potentially confound the underlying contribution factors in the observed patterns among the young adults (Collia et al., 2003; Figueroa et al., 2014).

According to the TCS2011 data, the household interview survey covered 65,758 young adults (aged 18-59) and 20,062 elderly respondents (aged 60 or above). A total of 91,242 trips were taken by young people aged 18-59 and 14,211 were taken by the elderly aged 60 or above. The elderly are not a homogenous group, as mobility characteristics and travel patterns might vary among subgroups (Alsnih and Hensher, 2003; Hildebrand, 2003; Truong and Somenahalli, 2015). Previous studies confirmed that travel activities are agerelated. The mobility and willingness to travel decreased as people aged (Johansson-Stenman, 2002; Collia et al., 2003; Somenahalli and Shipton, 2013; Figueroa et al., 2014). Therefore, to gain a deeper understanding of travel behavior of the elderly and examine how such behavior differed across age cohorts, this study followed similar studies (Alsnih and Hensher, 2003; Newbold et al., 2005; Horner et al., 2015) and categorized them into three finer cohorts: aged 60-69, 70-79, and 80 or above.

Table 1

Mechanized trip rates of people in different age cohorts.

\begin{tabular}{|c|c|c|c|c|}
\hline \multirow{2}{*}{ Parameters } & \multicolumn{4}{|c|}{ Age Groups } \\
\cline { 2 - 5 } & $18-59$ & $60-69$ & $70-79$ & $80+$ \\
\hline Expanded number of respondents & $4,493,381$ & 679,138 & 406,471 & 255,977 \\
\hline Expanded number of trips & $6,238,407$ & 621,578 & 237,749 & 91,810 \\
\hline Mechanized trip rate & 1.39 & 0.92 & 0.58 & 0.36 \\
\hline
\end{tabular}

After applying the expansion factors to the collected data for a better representation of the population's travel patterns, about 5.8 million more respondents with over 7.2 million 
expanded mechanized trips in a day were obtained for further statistical analysis. Table $\mathbf{1}$ reports the mechanized trip rates on a typical weekday for young adults and the elderly. The trip rates varied considerably across different age groups, gradually declining from 1.39 to 0.36 trips (a decrease of up to $74 \%$ ) as people age. The results indicated that older adults tended to be less mobile than their younger counterparts, and the former generated significantly fewer mechanized trips per day in comparison. As suggested by Mollenkopf et al. (2017), this phenomenon is possibly due to their poor physical conditions, difficulties of using transport modes, and environmental barriers. Also, the majority of the elderly population was retired, and thus they did not have the incentive or income to support unnecessary travel. Furthermore, due to deficits in sensory function and musculoskeletal strength, the elderly were more sensitive to rough and uncomfortable rides and became tired more easily on long journeys, especially when travelling without a seat.

\section{Table 2}

Mechanized trip rate analysis-Market segmentation analysis of people with different sociodemographic characteristics.

\begin{tabular}{|c|c|c|c|c|c|c|c|c|}
\hline \multirow{2}{*}{ Market Segment } & \multicolumn{7}{|c|}{ Gender and Age Groups } \\
\cline { 2 - 10 } & \multicolumn{9}{|c|}{ Male } & \multicolumn{5}{c|}{ Female } \\
\cline { 2 - 9 } & $18-59$ & $60-69$ & $70-79$ & $80+$ & $18-59$ & $60-69$ & $70-79$ & $80+$ \\
\hline With a full-/part-time job & 1.65 & 1.45 & 1.45 & 1.36 & 1.47 & 1.42 & 1.64 & 1.63 \\
\hline Without a full-/part-time job & 0.98 & 0.73 & 0.59 & 0.41 & 0.84 & 0.71 & 0.52 & 0.28 \\
\hline With a driving license & 1.66 & 1.28 & 1.18 & 1.18 & 1.69 & 1.37 & 1.53 & 0.71 \\
\hline Without a driving license & 1.46 & 0.87 & 0.59 & 0.40 & 1.18 & 0.78 & 0.52 & 0.28 \\
\hline Multi-person household & 1.56 & 1.02 & 0.64 & 0.42 & 1.24 & 0.80 & 0.52 & 0.08 \\
\hline Single-person household & 1.39 & 0.91 & 0.70 & 0.42 & 1.51 & 0.98 & 0.64 & 0.22 \\
\hline
\end{tabular}

To analyze the mechanized trip rates of young adults and the elderly with different socio-demographic characteristics, a market segmentation analysis based on age, gender, occupation status, having a driving license, and living in a multi-person household, is conducted and the results are tabulated in Table 2. In most of the cases (17 out of 24 cases), the trip rates of men were larger than those of women. The finding is in line with other gender travel studies (Collia et al., 2003; Su and Bell, 2012). For the people with a full-/part-time job, they made compulsory commuting trips for work and hence had a higher trip rate. Having a driving license is related to higher trip rates for both men and women in all age groups. The female residents in a single-person household traveled more than their counterparts in a multiperson household. Perhaps it is because women were responsible for housework in a multiperson household, and thus they make fewer trips than men in their families. By contrast in single-person households, both genders are equally responsible for housework. The differences of trip rates between genders in a single-person household were, therefore, less obvious.

\subsection{Journey time: How long/far did the elderly go?}

Fig. 2 illustrates the proportion of trips by journey time for the respondents in the different age cohorts and genders. Note that male and female residents had a similar travel pattern on journey time. The proportions for all of the age cohorts reached their peaks in the journey time group at between 21 and 30 minutes, and less than 5\% of the trips lasted more than an hour. The majority of the mechanized trips were completed within 30 minutes for the elderly. The proportion of the elderly's trips rapidly dropped from around $40 \%$ to $10 \%$ when 
the journey time exceeded 30 minutes. The decreasing trend was less obvious for young adults' trips, where still more than 20\% were completed in 51-60 minutes. The findings revealed that most of the elderly traveled for a short trip for less than 30 minutes journey time, while the young respondents made more long trips than their senior counterparts. It is worth mentioning that the length of journey time was not entirely equivalent to the actual travel distance, which depended on the transport modes used and their corresponding average traveling speed. Considering that more elderly individuals preferred slower transport modes for cheaper travel fares and more stable rides, the actual travel distance was anticipated to be more divergent between young adults and the elderly.
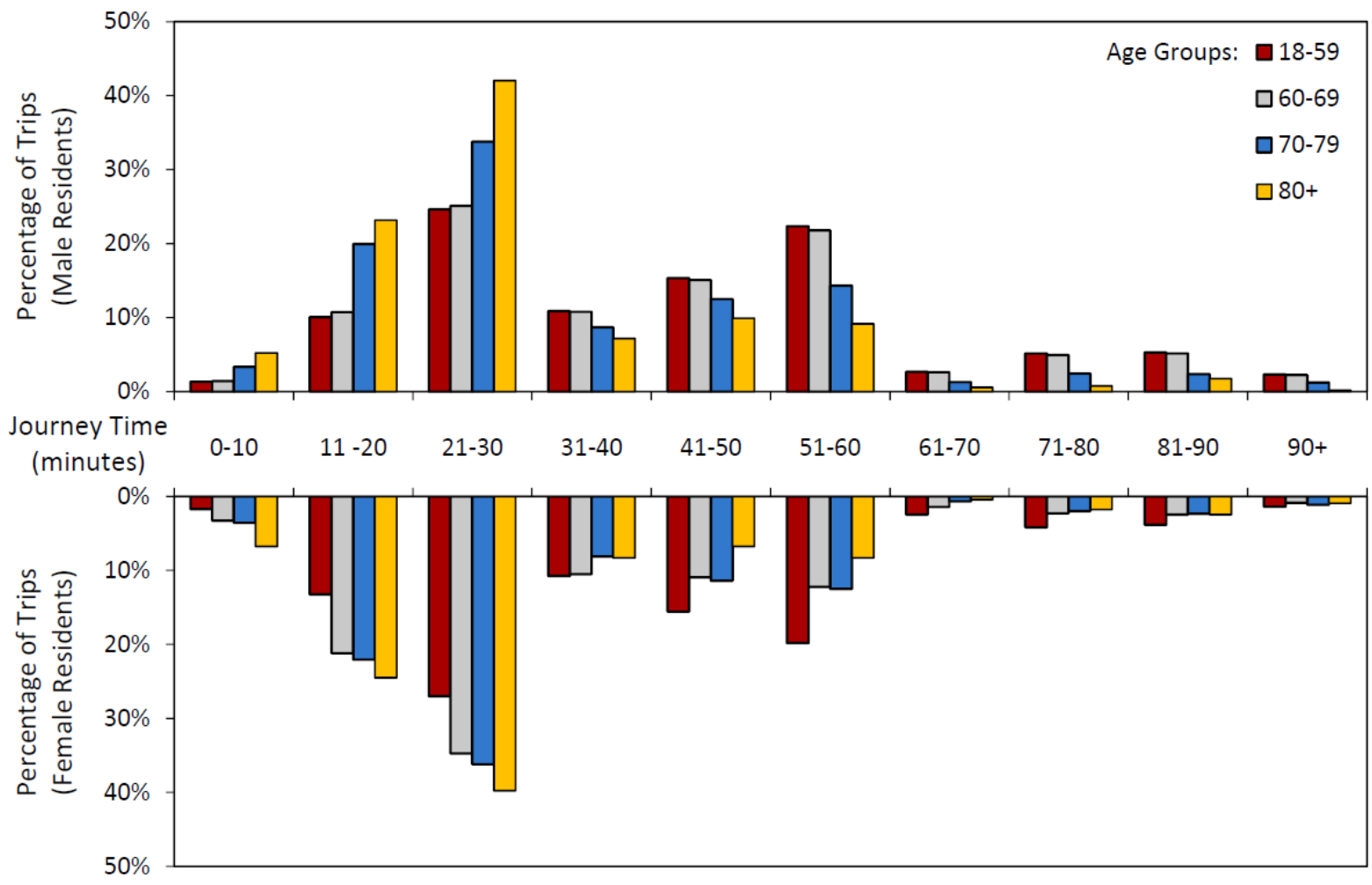

Fig. 2. Distribution of trips by journey time for people in different age cohorts and genders.

\subsection{Mode Choice: How did the elderly travel?}

The following mechanized transport modes were categorized in this study: 1) Mass Transit Railway (MTR), 2) Light Rail Transit (LRT), 3) tram, 4) ferry, 5) public light bus, 6) franchised bus, 7) private vehicle, 8) taxi, 9) special purpose bus (local shuttle bus, resident's service, direct cross-boundary coach, cross-boundary shuttle bus, company coach, school bus, and tourist coach), and 10) others (golf cart and ambulance vehicle). Fig. 3 presents the public transport mode choices of the different age cohorts and genders. Unlike many Western nations in which cars are the dominant travel mode and adequate alternatives are extremely unpopular, public transport is by far the most frequently used mode by all age cohorts and genders in Hong Kong, representing over 92\% of the total ridership. MTR, franchised bus, and public light bus were the three most popular transport modes out of all of the segments. MTR was the most favorable mode for young adults, comprising about a total of $35 \%$ of their daily trips, whereas franchised bus constituted the highest percentage of daily travel for old adults. We observe a steady increasing trend for old men using franchised bus as they aged, while there was a slight drop of franchised bus usage for old women aged 80 or above, who traveled more frequently by LRT and other transport modes than their counterparts of male aged 80 or above. 
A few possible explanations of the elderly preferred using franchised bus services, in general, are as follows: cumbersome MTR interchange experiences (they are required to walk a long way to the next platform inside train stations to transfer); shorter walking distance for franchised bus services (franchised buses offered point-to-point direct services with fewer interchanges and more frequent stops on streets, and they did not have to walk downstairs to underground MTR stations); and seat availability (MTR was always crowded, with a limited provision of seats, but the elderly had a higher chance of finding a seat on a bus). In addition, the elderly enjoyed traveling more by tram due to cheaper travel fares, and by taxi due to higher accessibility. In contrast, the usage of private vehicles decreased with age, perhaps due to the additional car licensing restrictions for those aged 70 or above.

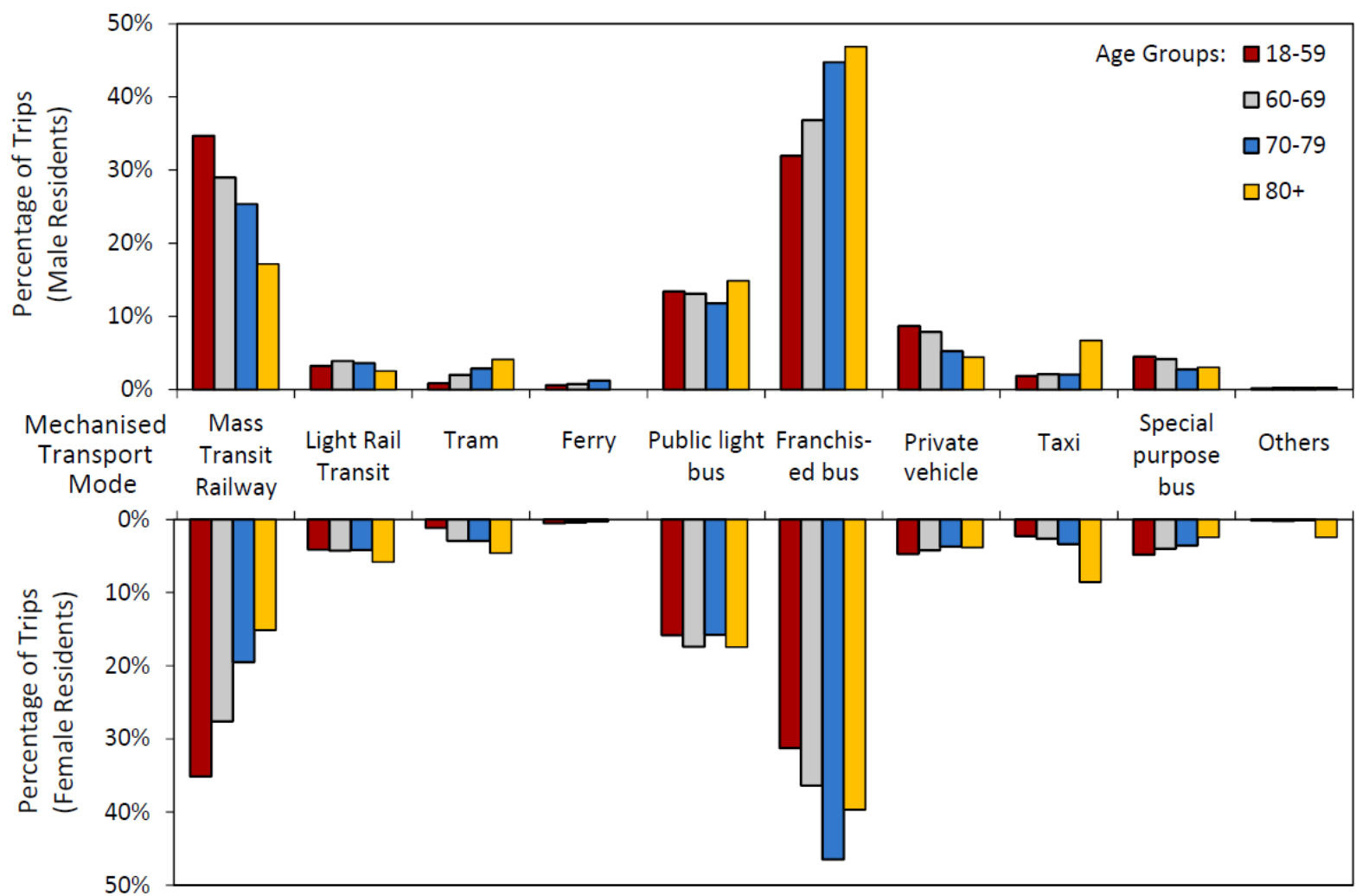

Fig. 3. Distribution of trips by mechanized transport modes for people in different age cohorts and genders.

\subsection{Trip Purpose: What did the elderly do?}

Trips were categorized by purpose: work, school, market (shopping), food premise (dining in a restaurant), exercise, medical care, culture, elderly homes, visiting friends, and other (some low-frequency trips, e.g., entertainment, religion, financial affairs, going to mainland China, escorting schoolchildren to and from school, etc.). As illustrated in Fig. 4, the trip purposes of the young and older adults varied significantly. The most striking difference was that the proportions of the elderly's work and school trips were greatly lower than those of young adults. Work trips accounted for the greatest share (73\% for male and $60 \%$ for female) for the younger group, and it gradually decreased to less than $4 \%$ for the respondents aged 80 or above. Work was still the dominant trip purpose for old men aged 60-69, while old women aged 60-69 traveled most for shopping. The retirement age in Hong Kong is typically 60-69, but a proportion of people in this age group still had full- or part-time jobs. School trips constituted over $5 \%$ of the daily trips of young adults, but almost none for the elderly cohorts. Market (shopping) and food premise (dining in a restaurant) were the two dominant trip 
purposes for those aged 70-79 and 80 or above, but it only accounted for not more than 20\% of young adults' trips in each case. Furthermore, the elderly travelled more frequently to hospitals, medical centers, and clinics for medical care and to the park, playground, sports grounds, and gym centers for exercise than their younger counterparts. The elderly were more usual to visit their friends than young adults.

The above details indicate that people move from attending school, to joining the labor force, and to retirement in a step-by-step manner as they age. The frequent trip purposes changed from mandatory trips (work and school) to optional trips (household-sustaining and leisure).

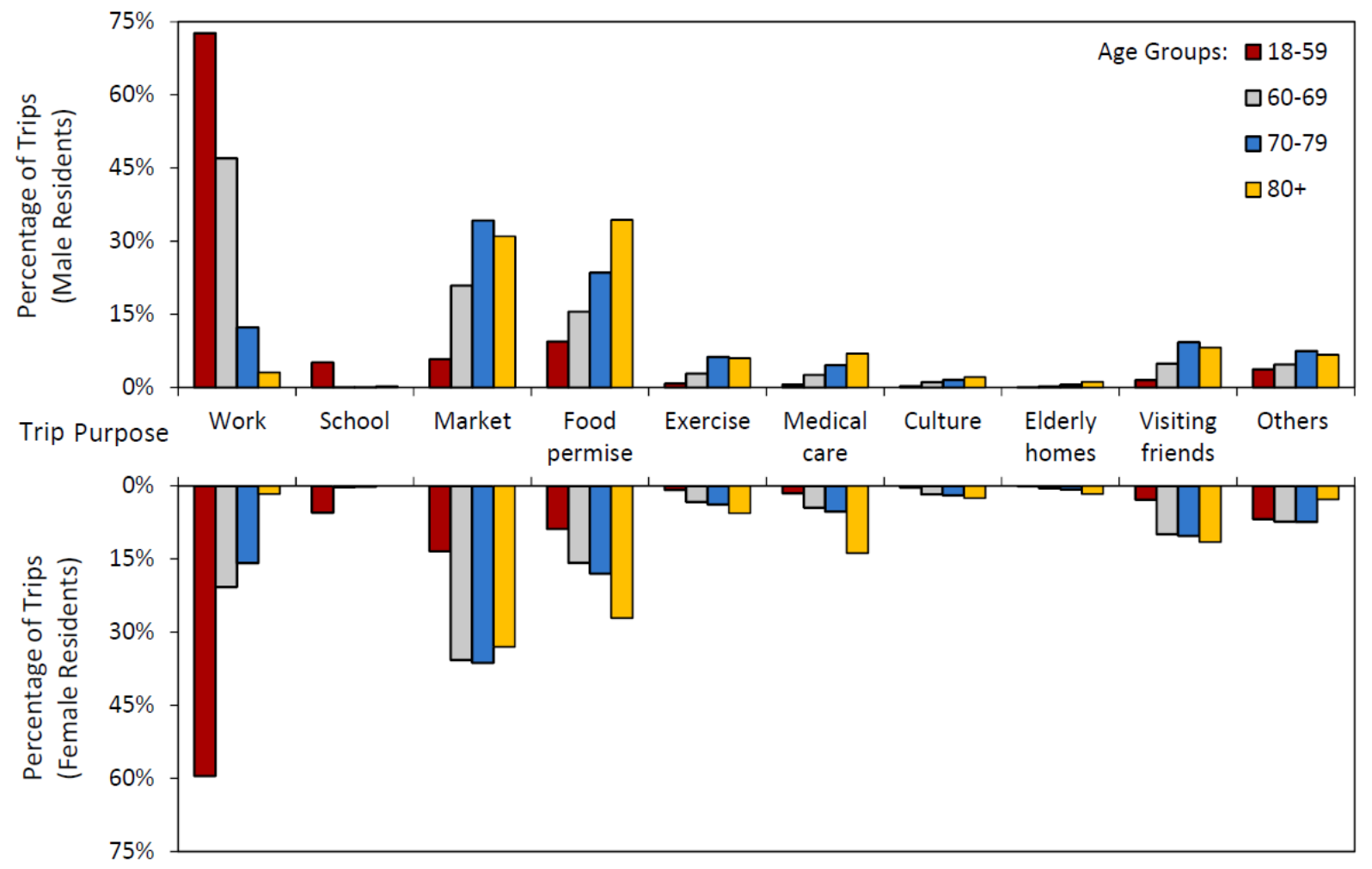

Fig. 4. Distribution of trips by purpose for people in different age cohorts and genders.

\subsection{Trip start time: When did they go?}

Fig. 5 shows the start times of the respondents' trips over different hourly periods in a day. Two obvious peaks were identified between 7 am and $10 \mathrm{am}$ in the morning (defined as morning peak hours, and highlighted in red), and between $5 \mathrm{pm}$ and $8 \mathrm{pm}$ in the evening (defined as evening peak hours, and highlighted in blue). These periods aligned with typical office hours, which accounted for $62 \%$ of the young adults' trips. During these two peak commuting periods, the elderly travelled much less, which demonstrates that they tended to avoid travelling with their younger counterparts, probably because they preferred staying away from crowds. Because they were retired, the elderly travelers could alter their trip start times for a more comfortable travel environment. In contrast, the elderly respondents travelled more frequently during the noon off-peak hours from 10 am to $5 \mathrm{pm}$. Their probability of making a trip after $8 \mathrm{pm}$ was usually lower than that of the younger group (less than $5 \%$ of total trips in a day for each sub-group in the elderly population). This indicates that the majority of elderly adults preferred not to travel at night. The finding is consistent with that of Alsnih and Hensher (2013), who indicated that older adults were more active outside the home during daylight hours than after dark. 
The trip-making pattern of the elderly aged 60-69 was similar to that of the young respondents when compared with those of the elderly aged 70-79 and 80 or above. It is interesting to note that the travel patterns gradually transformed as people aged. Some of older adults aged 60-69 had full- or part-time jobs and made compulsory trips during peak commuting hours. Hence, more trips started during rush hours, but the distribution was more even than that of the young adults' trips. For the elderly aged 70-79, the trip start times shifted to noon off-peak hours, and only one peak could be identified. Once the respondents had reached age 80 or above, they had a higher tendency to start their trips during the 10 am to 11 am period to avoid traveling with crowds. It is worth mentioning that the difference in trip start times between male and female was small, and hence it is not presented in Fig. 5.

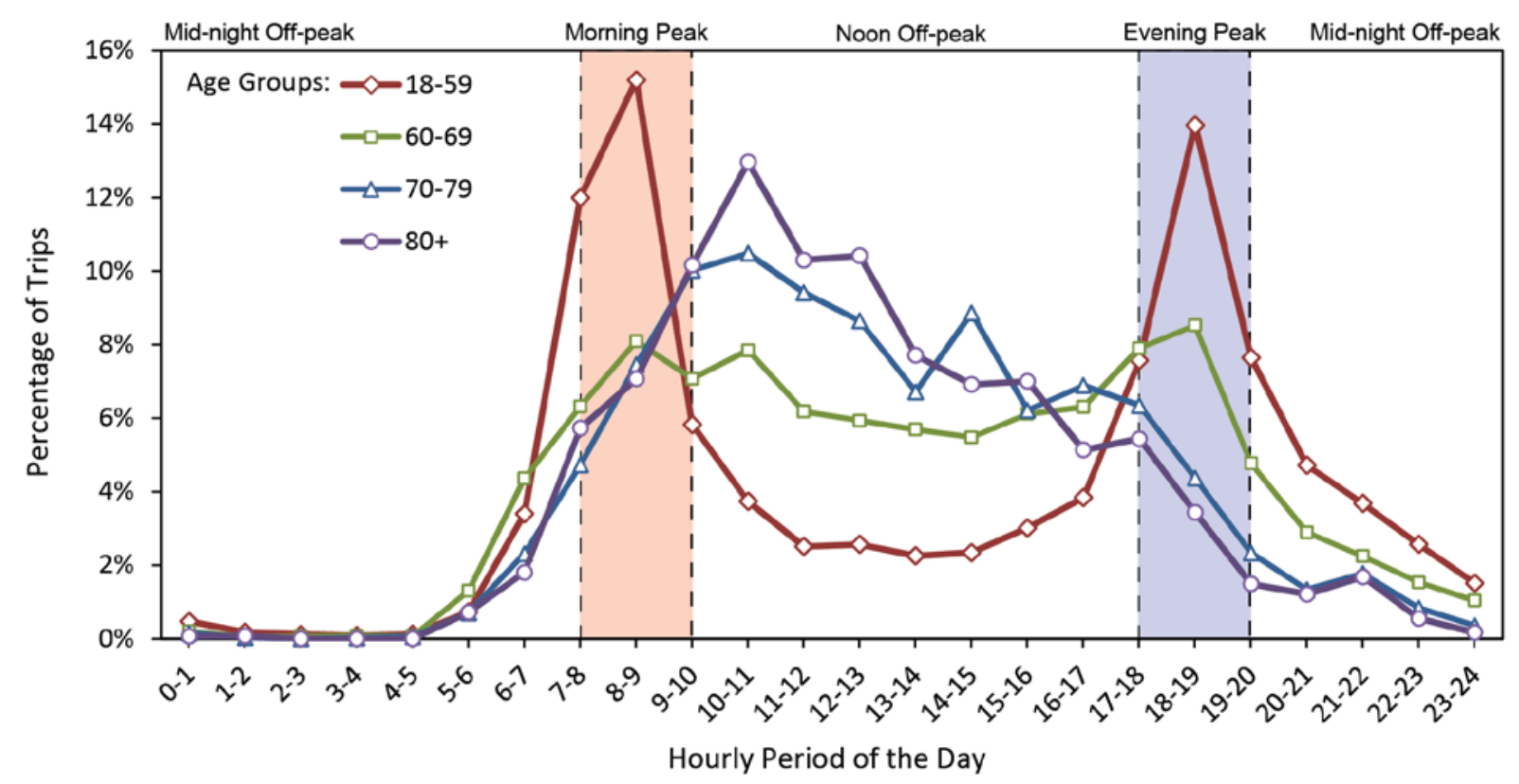

Fig. 5. All-day profile of trip start times for people in different age cohorts.

\section{Spatio-temporal travel characteristics}

We also conducted a spatio-temporal analysis to investigate how the respondents' travel behavior related to space and time. According to the discussion in the previous section, four study periods (morning peak, noon off-peak, evening peak, and midnight off-peak) were identified. Fig. 6 provides a visualized demonstration of the popularity of 26 destinations during these periods among young adults and the elderly. The darkness of a zone represents its level of popularity or attractiveness (calculated as the proportion of trips to a specific zone during a specific period over the total number of trips in a day for each age cohort). There are noticeable differences between two groups in terms of their spatio-temporal distributions. The young adults concentrated their travel during the two peak commuting hours, whereas the elderly preferred travelling during the noon off-peak period.

During the two peak periods, young adults took a higher percentage of trips (33\% and $29 \%$ in the morning and evening peak hours daily, respectively), with the majority being compulsory (work and school) trips. During the morning peak, the most popular zones were commercial districts, including Central and Western (3.8\%), Kwun Tong (2.8\%), and Wan Chai (2.6\%). The most popular zones during the evening peak were residential districts, including Kwun Tong (2.5\%), Eastern (2.4\%), and Tuen Mun (2.1\%). Interestingly, Kwun Tong exhibited a better job-housing balance, and its town planning setting decreased the 
number of vehicle trips and long-distance commuting demands in addition to relieving traffic congestion (Cervero, 1989, 1991; Giuliano, 1991; Loo and Chow, 2011). 

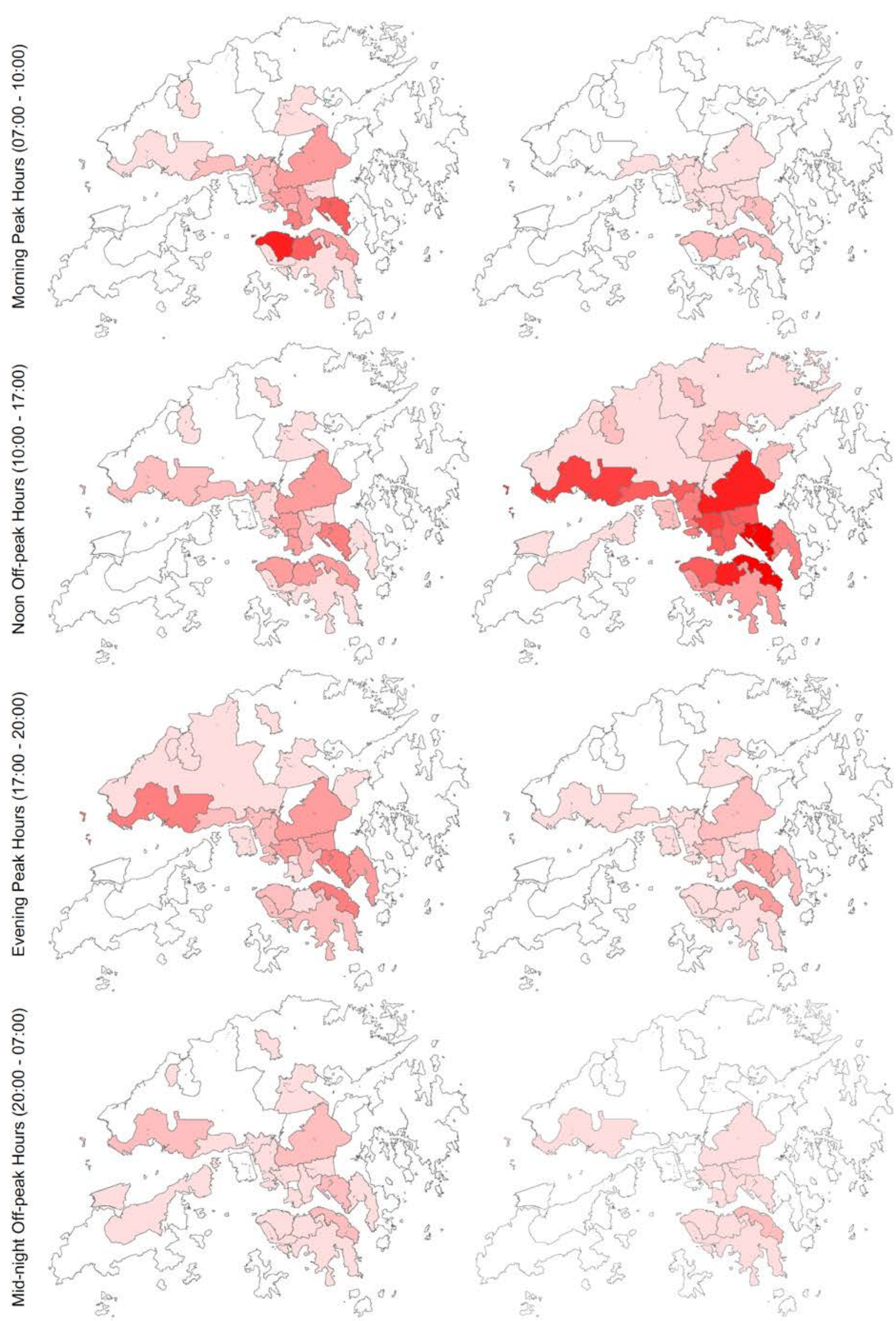

Fig. 6. The level of trips' attractiveness during the four study periods. 
The majority of the elderly respondents' daily trips (57\%) were generated between 10 am and 5 pm; specifically, 22\%, 18\%, and 12\% of the trips were taken in the morning peak, evening peak, and midnight off-peak hours, respectively. This indicates that older adults preferred to avoid traveling during the peak commuting hours and at night. Seven of the zones (Kwun Tong, Eastern, Wan Chai, Sha Tin, Sham Shui Po, Tuen Mun, and Central and Western) were the most popular among the elderly during the noon off-peak hours, with each zone attracting over $3 \%$ of daily trips.
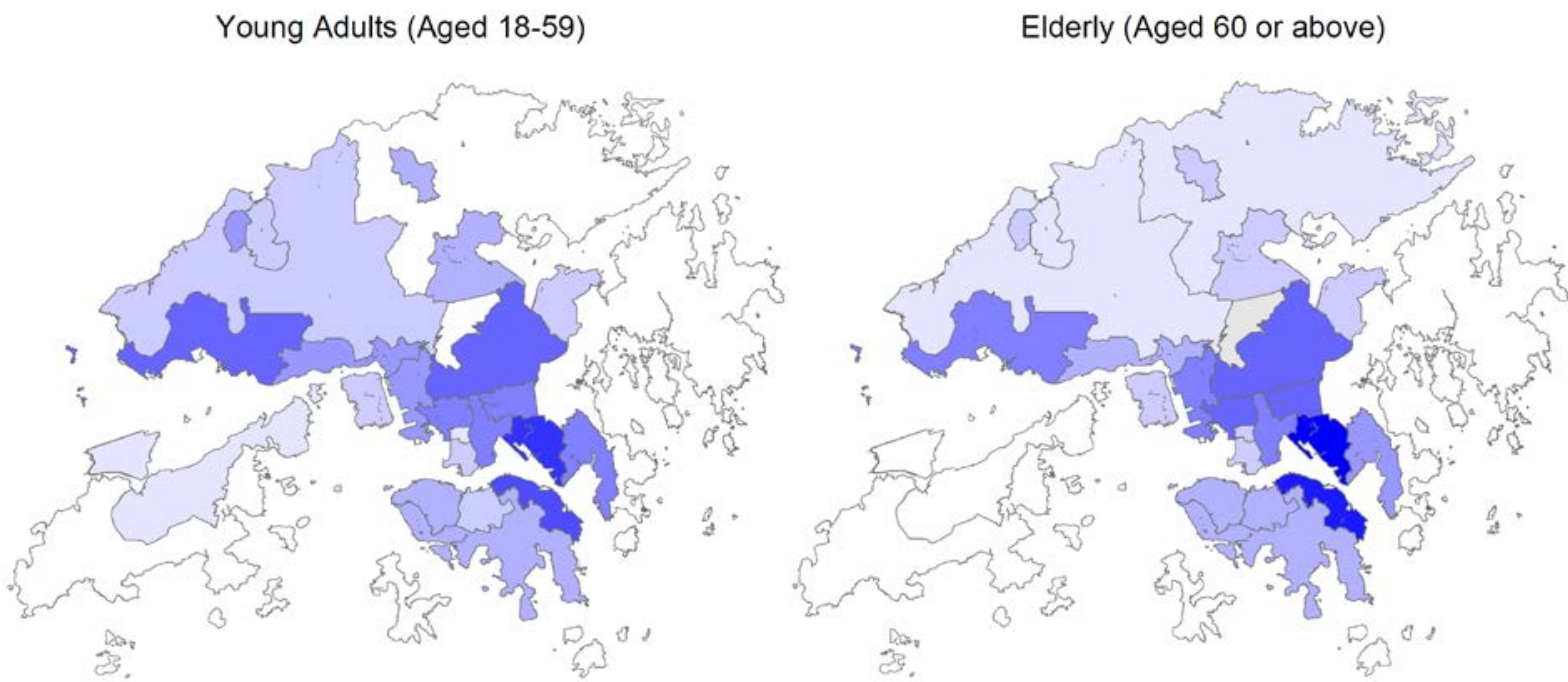

Fig. 7. Population distribution of young adults and the elderly.

Some zones were more attractive to young adults or to the elderly, overall. In terms of the most divergent destination for both groups, Central and Western attracted $7.6 \%$ of the young adults' trips and only $5.4 \%$ of those made by the elderly. In contrast, Eastern attracted $9.4 \%$ of the trips made by the elderly and only $7.5 \%$ of the young adults' trips. These travel patterns could be explained by trip purpose (as mentioned above) and population distribution. Fig. 7 demonstrates the population distribution of young adults and the elderly. The darker zones represent the greater population. Note that the population distributions of these two groups were somewhat similar. The majority of Hong Kong residents lived in urban areas, particularly concentrated in the Kwun Tong and Eastern zones. A deeper analysis of Figs. 6 and 7 reveals that the young adults' trip destinations were more dispersed due to the obvious differences between the population distribution and trip destination distribution for this group. Among the elderly, the population distribution was similar to the trip destination distribution, indicating that the zones more frequently visited by the elderly had higher elderly populations. A possible explanation is that the elderly made more short (intra-zonal) trips, in line with our previous observations regarding shorter journey times for trips taken by the elderly.

\section{Policy insights}

The public transport services' ability to address the needs of their elderly passengers is of particular concern. The elderly are transit captives who rely heavily on public transport in Hong Kong. Understanding the unique travel behavior of older adults provides the basis for policy instruments. It is the first step for city governments to take in establishing effective and appropriate public transport policy measures for the elderly. Based on the aforementioned travel patterns and characteristics of the elderly, we summarize the following four 
observations that provide policy insights into improving public transport services for the elderly.

1. The mechanized trip rate declined significantly (dropped up to 74\%) as people aged.

2. The elderly respondents aged 80 or older usually made short trips, travelling less by MTR and franchised bus and more by taxi and other modes (e.g., ambulance).

3. The elderly respondents preferred public transport modes with fewer interchanges and shorter walking distances, and they preferred traveling during the noon off-peak hours between 10 am to 5 pm to avoid crowds.

4. Most of the elderly respondents lived in particular zones (Kwun Tong and Eastern) and frequently made intra-zonal trips near their living places.

\subsection{Public transport concession fare scheme and provision of priority seats}

To address the first problem of the lower mechanized trip rate among the elderly, the Hong Kong government recently implemented public transport concession fare schemes (started from June 2012, and implemented in several phases) for four public transport modes (MTR, franchised buses, public light buses, and ferries) to subsidize the elderly aged 65 or above by allowing them to travel any time for a concession fare of HK\$ 2 per trip. However, given that the mechanized trip rate declines as people age, introducing a stepwise subsidy scheme to the elderly in different age cohorts could be more effective in encouraging them to travel and participate in social activities. It has been noted that more elderly individuals are retiring at the age of 60, but must still pay full-price for public transport until the age of 65 . A scheme that subsidizes those aged 60-64 years with a discount (e.g., half-price) would improve their mobility. Such travel fare discounts would provide additional incentives for retired elderly individuals aged 60-64 to travel. In contrast, the trip rate of the elderly respondents aged 80 or above was the lowest. The public transport concession fare schemes may consider entirely waiving the travel costs of this group to encourage mobility. This approach has proven effective in enhancing elderly mobility in Britain (Baker and White, 2010). Moreover, the existing schemes only cover four public transport modes. An extension to other modes is worth exploring.

In Hong Kong, priority seats for people with special needs were first introduced in 2009 on MTR and franchised buses to encourage the elderly to travel by these public transport modes and participate more in social activities. Nonetheless, the elderly often have to stand because priority seats are limited and occupied by other passengers. Many passengers have little awareness of offering seats to the elderly around them. A recent study revealed that mobile phone and tablet use is the main reason that passengers neglect to offer seats to the needy on public transport (Department of Applied Social Sciences, 2015). Thus, the concern about insufficient priority seats cannot simply be addressed by providing more of them. Making it mandatory for users to offer seats to their counterparts with special needs through legislation would be difficult and impractical. Thus, to address this problem, the culture of offering seats to the needy should be promoted through education.

\subsection{Age-friendly public transport system and alternative transport options}

MTR and franchised bus were found to be the most popular public transport modes for the elderly in Hong Kong. However, a decrease in patronage has been observed as people age and start to travel more by taxi and ambulance for their medical care trips. However, these modes are not financially sustainable and thus are inappropriate for frequent or daily use. To resolve this issue, the provision of an age-friendly public transport system is suggested. Refer to the suggestions provided by Shiau and Huang (2014) about the age-friendly improvement 
strategies for transit services in Taipei. Ease of boarding and alighting, conditions of stations and stops, and drivers' attitudes can all be improved.

To improve the elderly's accessibility to transit services, low platform buses and escalators connecting underground MTR stations and streets are suggested. Seats and shelters are also recommended for those waiting for service. Although it may not be feasible to provide sufficient shelters and seats at all bus stops and public light bus stops due to the limited road space in congested urban areas, caused by narrow footways or inadequate headroom clearance, these facilities could be strategically placed at locations typically frequented by the elderly, such as outside hospitals, district elderly community centers, social centers, and non-subverted service centers for the elderly. Public transport drivers should pay special attention to the elderly passengers on board. Public transport operators should, therefore, provide appropriate training and guidance for their drivers to enhance awareness about driving behavior and attitude, followed by the timely evaluation of drivers' performances.

In addition to improving the traditional transit modes, Whelan et al. (2006) pointed out that the elderly may need new and different types of public transport options that are viable, affordable, accessible, safe, and coordinated. Rahman et al. (2016) suggested numerous transportation alternatives for the elderly, including volunteer drivers, senior-center-based shuttle buses, prepaid taxi services, and specially coordinated bus/rail service to distant medical centers. Improving alternative transport options for the elderly in the forthcoming years is considered to be both indispensable and urgent.

\subsection{More frequent and direct public transport services during noon off-peak hours}

The number of interchanges reflects a trip's directness and convenience. The elderly are usually more interchange-averse due to their poor physical condition. To improve elderly mobility, the number of interchanges involved in public transport services should be minimized. However, to relieve traffic congestion caused by franchised buses, the Hong Kong government recently introduced bus-bus interchange schemes to promote interchanges at major bus stops and cancelled many of the direct bus routes that overlapped. These schemes have had adverse effects on travel among the elderly by suppressing their willingness to participate in social activities. The government should achieve a better balance between the overall traffic conditions and the travel demands of the elderly when planning direct bus services.

In the findings of this study, the elderly individuals concentrated their travel during the noon off-peak hours from 10 am to 5 pm to avoid crowds. We suggest that the direct bus services only operate during this window between the popular origins and destinations of the elderly (e.g., elderly community centers, social centers, markets, and non-governmentsubsidized service centers for the elderly, etc.). This would not worsen the traffic conditions during the most congested rush hours and would ensure better public transport services for the elderly. In cases where interchanges are unavoidable, volunteers or staff members could be recruited at stations and stops to help the elderly carry luggage and find their way.

According to population projection data for 2012-2041, the proportion of elderly people aged 60 or above is expected to reach 36.4\% in 2041 (Census and Statistics Department, 2012). Based on the travel patterns of the elderly, it is reasonable to anticipate that more people will travel during the noon-peak hours, alleviating the congestion level during the two commuting peak hours.

\subsection{Provide facilities in districts with concentrated elderly populations and encourage cross-} district travels 
Most of the elderly's trips were concentrated within specific board districts (Kwun Tong and Eastern). As the population distributions of the young and older adults were similar, it follows that population ageing will not significantly change how the elderly population is distributed. Hong Kong's government should, therefore, consider providing more permanent elderly facilities in those concerned districts to provide an age-friendly living environment that enhances their willingness to take part in community activities. Loo and Lam (2012) proposed improving pedestrian safety, comfort, and convenience for the older adults walking between major transit stops and major health care facilities for a walkable pedestrian environment to promote active ageing.

We should also continue exploring potential ways to encourage the elderly to make more cross-zonal trips for leisure purposes. For example, elderly community centers may consider organizing frequent day-trips to sightseeing hotspots in rural areas of the New Territories (e.g., wetland parks, nature reserves, monasteries, Buddha statues, etc.) with the provision of direct shuttle bus services. This would effectively enrich the health, well-being, and quality of life of the elderly from a social integration perspective.

\section{Conclusion}

Population ageing is happening in most countries around the world, and Hong Kong is no exception. The proportion of adults aged 60 or above in Hong Kong is predicted to reach $36.4 \%$ in 2041. Given that Hong Kong is a high-density, transit-oriented city, the predicted rapid growth of the region's elderly population is expected to significantly affect the existing public transport system. The first step is for the city government to offer age-friendly public transport systems for the elderly that consider their unique travel behavior and preferences.

In this study, we extracted the TCS2011 data describing the travel patterns of the elderly. We then made comparisons with people in other age cohorts and among subgroups of the elderly population. Next, the spatio-temporal travel characteristics of the elderly were visualized and uncovered, and some policy insights into how to improve public transport services for the elderly were discussed. The results can serve as a valuable reference to the city government in formulating effective and appropriate public transport policy measures to improve elderly mobility. These suggestions can also be applied to other metropolitan cities with similar transportation environments.

There are several limitations that deserve further research: 1) Phase one of public transport concession fare schemes was implemented in June 2012, a few months after the completion of household interview survey. A before-and-after study is recommended to evaluate the effectiveness of enhancing elderly mobility, and how the schemes changed the travel patterns of the elderly; 2) For the market segmentation analysis, this paper mainly divided old adults into segments based on two unambiguous criteria, chronological age and gender, for revealing travel patterns of the elderly across age cohorts. It helps us identify the variation in travel patterns as people age, and sheds light on introducing a stepwise subsidy scheme to the elderly in different age cohorts. Some other segmentation factors (e.g., attitude, health condition, financial status, and the built environment) can be considered for future studies (Haustein and Siren, 2015) when the corresponding personal particulars are available; and 3) Because of the limited information collected from the household interview survey, it is infeasible for us undertaking in-depth analysis to understand whether the elderly satisfy with the existing public transport services, what aspects should be improved in order to enhance their willingness to travel, and how much the mobility will increase if mitigation measures are 
implemented. Additional face-to-face questionnaire surveys with the elderly are suggested for the answers to the above questions.

\section{Acknowledgements}

This research was supported by a grant from the Central Policy Unit of the Hong Kong Special Administrative Region Government, Public Policy Research Funding Scheme (Project No.: 2014.A8.025.15B). The authors are grateful to the two reviewers for their constructive comments.

\section{References}

Alsnih, R., Hensher, D.A., 2003. The mobility and accessibility expectations of seniors in an aging population. Transportation Research Part A: Policy and Practice 37 (10), 903-916.

Baker, S., White, P., 2010. Impacts of free concessionary travel: Case study of an English rural region. Transport Policy 17 (1), 20-26.

Buehler, R., Nobis, C., 2010. Travel behavior in aging societies: Comparison of Germany and the United States. Transportation Research Record: Journal of the Transportation Research Board 2182, 62-70.

Census and Statistics Department, 2012. Hong Kong Population Projections 2012-2041. Hong Kong SAR Government, Hong Kong.

Cervero, R., 1989. Jobs-housing balancing and regional mobility. Journal of the American Planning Association 55 (2), 136-150.

Cervero, R., 1991. Jobs housing balance as public policy. Urban Land 50 (10), 10-14.

Choi, J., Lee, W.D., Park, W.H., Kim, C., Choi, K., Joh, C.H., 2014. Analyzing changes in travel behavior in time and space using household travel surveys in Seoul Metropolitan Area over eight years. Travel Behaviour and Society 1 (1), 3-14.

Collia, D.V., Sharp, J., Giesbrecht, L., 2003. The 2001 national household travel survey: A look into the travel patterns of older Americans. Journal of Safety Research 34 (4), 461470.

Cui, J.Q., Loo, B.P.Y., Lin, D., 2016. Travel behaviour and mobility needs of older adults in an ageing and car-dependent society. International Journal of Urban Sciences, DOI:10.1080/12265934.2016.1262785

Currie, G., Delbosc, A., 2010. Exploring public transport usage trends in an ageing population. Transportation, 37 (1), 151-164.

Department of Applied Social Sciences, 2015. Offering Seats Habits Reviewed from a Public Opinion Workshop, The Hong Kong Polytechnic University, Hong Kong. www.apssweb.polyu.edu.hk/news/Offering\%20seats\%20habits\%20revealed\%20from\%20 a\%20public\%20opinion\%20workshop.

Department of Environment, Transport and Regions, 2000. National Travel Survey: 1997/99 Update. Government Statistical Services, London, the United Kingdom.

Department of Transportation, 2011. Summary of Travel Trends: 2009 National Household Travel Survey, the United States.

European Environment Agency, 2009. Towards a Resource-efficient Transport System: Indicators Tracking Transport and Environment in the European Union. EEA Report, TERM 2009.

Figueroa, M.J., Nielsen, T.A.S., Siren, A., 2014. Comparing urban form correlations of the travel patterns of older and younger adults. Transport Policy 35, 10-20.

Financial Services and the Treasury Bureau, 2015. The 2013-14 Budget. Hong Kong SAR Government, Hong Kong. www.budget.gov.hk/2013/eng/budget27.html. 
Giuliano, G., 1991. Is Jobs-housing balance a transportation issue? Transportation Research Record: Journal of the Transportation Research Board 1305, 305-312.

Haustein, S., Siren, A., 2015. Older people’s mobility: Segments, factors, trends. Transport Reviews 35 (4), 466-487.

Hess, D.B., 2009. Access to public transit and its influence on ridership for older adults in two US cities. Journal of Transport and Land Use 2 (1), 3-27.

Hildebrand, E.D., 2003. Dimensions in elderly travel behaviour: A simplified activity-based model using lifestyle clusters. Transportation 30 (3), 285-306.

Horner, M.W., Duncan, M.D., Wood, B.S., Valdez-Torres, Y., Stansbury, C., 2015. Do aging populations have differential accessibility to activities? Analyzing the spatial structure of social, professional, and business opportunities. Travel Behaviour and Society 2 (3), 182191.

Hu, X., Wang, J., Wang, L., 2013. Understanding the travel behavior of elderly people in the developing country: A case study of Changchun, China. Procedia-Social and Behavioral Sciences 96, 873-880.

Ipingbemi, O., 2010. Travel characteristics and mobility constraints of the elderly in Ibadan, Nigeria. Journal of Transport Geography 18 (2), 285-291.

Johansson-Stenman, O., 2002. Estimating individual driving distance by car and public transport use in Sweden. Applied Economics 34 (8), 959-967.

King, M.J., Scott-Parker, B.J., 2016. Older male and female drivers in car-dependent settings: How much do they use other modes, and do they compensate for reduced driving to maintain mobility? Ageing and Society, 1-19, DOI: 10.1017/S0144686X15001555.

Loo, B.P.Y., Chow, A.S., 2011. Jobs-housing balance in an era of population decentralization: An analytical framework and a case study. Journal of Transport Geography 19 (4), 552562.

Loo, B.P.Y., Lam, W.W.Y., 2012. Geographic accessibility around health care facilities for elderly residents in Hong Kong: A microscale walkability assessment. Environment and Planning B: Planning and Design 39, 629-646.

Mollenkopf, H., Hieber, A., Wahl, H.W., 2017. Continuity and change in older adults' out-ofhome mobility over ten years: A qualitative-quantitative approach. In Knowledge and Action. Springer International Publishing, 267-289.

Newbold, K.B., Scott, D.M., Spinney, J.E., Kanaroglou, P., Páez, A., 2005. Travel behavior within Canada's older population: A cohort analysis. Journal of Transport Geography 13 (4), 340-351.

Olawole, M.O., Aloba, O., 2014. Mobility characteristics of the elderly and their associated level of satisfaction with transport services in Osogbo, Southwestern Nigeria. Transport Policy 35, 105-116.

Rahman, M.M., Strawderman, L., Adams-Price, C., Turner, J.J., 2016. Transportation alternative preferences of the aging population. Travel Behaviour and Society 4, 22-28.

Rosenbloom, S., 2004. The mobility needs of older Americans. In Katz, B., Puentes, R. (Eds.) Taking the High Road: A Metropolitan Agenda for Transportation Reform. Brookings Institution Press, 227-254.

Siren, A., Haustein, S., 2016. How do baby boomers' mobility patterns change with retirement? Ageing and Society 36 (5), 988-1007.

Shiau, T.A., Huang, W.K., 2014. User perspective of age-friendly transportation: A case study of Taipei City. Transport Policy 36, 184-191.

Somenahalli, S., Shipton, M., 2013. Examining the distribution of the elderly and accessibility to essential services. Procedia-Social and Behavioral Sciences 104, 942-951.

Su, F., Bell M.G.H., 2012. Travel differences by gender for older people in London. Research in Transport Economics 34 (1), 35-38. 
Tacken, M., 1998. Mobility of the elderly in time and space in the Netherlands: An analysis of the Dutch National Travel Survey. Transportation 25 (4), 379-393.

Transport Department, 2014. Travel Characteristics Survey 2011 Final Report. Hong Kong SAR Government, Hong Kong.

Truong, L.T., Somenahalli, S.V., 2015. Exploring frequency of public transport use among older adults: A study in Adelaide, Australia. Travel Behaviour and Society 2 (3), 148-155.

United Nations, 2015. World Population Aging 2015. United Nation Publication, New York, the United States.

van den Berg, P., Arentze, T., Timmermans, H., 2011. Estimating social travel demand of senior citizens in the Netherlands. Journal of Transport Geography 19 (2), 323-331.

van den Berg, P., Kemperman, A., de Kleijn, B., Borgers, A., 2016. Aging and loneliness: The role of mobility and the built environment. Travel Behaviour and Society 5, 48-55.

Whelan, M., Langford, J., Oxley, J., Koppel, S., Charlton, J., 2006. The Elderly and Mobility: A Review of the Literature. Monash University Accident Research Centre, Australia. 